\title{
Manipulation of Bio-nanotechnology in Agri-Sector for Pest Control with Special Emphasis to Nematode Problems in Egypt
}

SANAA A. HAROON

Fayoum University, Faculty of Agriculture, Plant Protection Department

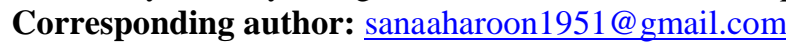

\begin{abstract}
With the extravagant increase in the population and the increasing need for food, space and desert development, especially for agricultural expansion, has become a strategic goal and the focus of the economic and social policies of Egypt .The coming decades will witness accelerated rates of development in desert agriculture, not only through expanding beyond the green boundaries of the delta and the Nile valley, but also by crossing to remote areas in Sinai, southern Egypt. Soil nematode infecting plants are one of the most destructive parasites worldwide and cause crop damages with wide host rang. Attacking plant root system and feed on the plant nutrients causing lose in the crop yield and even death of the plants by developing galls and necrosis in the root system losing the ability of absorb the nutrients, water and die. The current major issue concerning nematode damage to plants is the lack of effective chemical treatment methods. The public concern over the chemical Nematicides is not only their toxicity for health and environmental risks but also their loss of efficiency after prolonged use. Several control strategies alternative to chemical control that develops recently is production of natural Bio-Nano Nematicides as (green chemical) which act as inhibitors against nematodes population in soil. The Advantages of using bionano Nematicides, it's safe organic compound extracted from the plant, It has no residual effect, It gives high ability to reach within the roots to combat nematodes in their phases, and the ability of the compound to rapidly spread in irrigation water which also gives the strength to spread and stay in the soil for a long time. The nematicides caused direct death to nematodes after few minutes when exposed to low concentrations, also has a repellent effect due to the presence of nanoparticles around the roots, the penetration of nanoparticles inside the root causes the inability of nematodes to form the nourishing cells and are therefore destroyed. It was also found out that there are more than 800 products as fertilizers in the world with their effective as nanomaterials, it is used for sprinkling on the vegetable, which will benefit the plant faster by Increasing photodynamic activity also increasing leaf content of chlorophyll. Also that product Increase crop capacity to withstand different stress conditions, Absorption speed, and Only $1 \mathrm{~kg}$ of nanophosphate fertilizer is required to replace 150 to $200 \mathrm{~kg}$ of superphosphate fertilizer in citrus farms. For example, Nanomaterials help protect the environment and human health, Increases farm profitability due to reduced fertilizer and spraying costs. Finally Advantage of using Bio-nanotechnology application in agriculture is seriously contributes effectively to increase the productivity of crops, Increase the quality of fruits, Increase their competitiveness by reducing the residues of fertilizers, Preserves the soil and reduces the contamination of groundwater with the residues of different fertilizers, Economically reflected on the economic yield of the farmer through the reduction of expenses, and thus increase the profitability of different crops, and increase export opportunities through increased product competitiveness .

More over the Development of the new generation of highly specialized biocides, overcoming the problems of global warming and its impact on the growth of plants to produce plants that tolerate high temperatures.
\end{abstract}

Keywords: Green chemistry - Root knot nematode - Bio-Nematicides

\section{Introduction}

In recent years, many studies and research have emerged that deal with the introduction of nanotechnology in agricultural field, (AgroNanotechnology) among the most important promising studies is the use of nanotechnology in food preservation and pest control and production of specific sensors .

Recently, Nano materials used in agricultural fertilization as an effective alternative to traditional fertilizers with competitive prices and lower quantities that can be stored for longer periods as a result of their high stability under different conditions.

Our research area in Fayoum University are concentrated in controlling plant nematode which is consider as a significant past not only in Egypt but all over the world, it damage most agricultural crops reducing the yield and quality that valued reach approximately at over $\$ 75$ billion worldwide (luc et al 2006).

Melodigine spp is the most important species of plant nematode, it distributed globally, and is the most serious soil born sedentary endoparasitie pest which infects wide range of host plants leading to great crop losses. $M$. incognita population leads to, suppression of plant growth, fruit yield, leaf browning and reduction of photosynthetic pigments (khan and saxena,2017) extensive research has been carried out in most countries regarding the destructive nature of these nematodes. Multinucleated cells were develop inside the root system to serves as permanent feeding sites for M.incognita female which lay eggs within the roots surrounding the rhizosphere soil and provide 
nutrition for developing the second stage to complete its short life cycle of 25 to 40 days. The nematode Causing severe injury to the plants which leads to others problems followed by poor crop nutrition when Crops that infected with significantly large number of M.incognita population, the plant roots were weakens, the root failed to take up water and nutrition leading to unhealthy and non-uniform plant growth followed by chlorosis and stunting, formation of knots and galls lesions on roots. In susceptible plants, the nematode population build up to a maximum level, as crop reaches maturity and some plants die even before reaching maturity which effect plant quality and quantity (singh and khurma, 2007).

Traditional control strategies such as crop rotation resistant varieties, and solarization which include in IPM programs that have been used by Egyptian farmers for nematodes management in agriculture lands. IPM was introduced and developed as a solution to avoid the side effect of Nematicides, in the 1990s when the IPM began in Egypt to be promoted as a pest control strategy, there were only few IPM technologies available for field application. Extensive research on the management of nematode pest generated some novel products and knowledge for successful implementation of IPM in crops such as most Fruits and vegetables. However, the exaggerated expectations about the possibility that dramatic reduction in pesticide use could be achieved without significant decline in crop yields as a result of adoption of IPM could not be realized (Dhawan and Peshin 2009).

The above-mentioned limitations and less efficiency of traditional methods lead to the development of new and modern approaches for management Nematode pest especially in desert cultivated land which is extremely important for agri production. Keeping in mind the applications of nanotechnology in agriculture, it can be suggested that the use of Nano materials could be result for developing an efficient and potential approaches for the management of nematode as potential modern approach.

Previous studies confirmed that metal nanoparticles are effective against plants pathogens and pests. Hence, nanoparticles can be used in the preparation of new formulations like pesticides or Nematicides.

According to Wang et al. (2007), oil in water (Nano-emulsions) was useful for the formulations of pesticides and these could be effective against the various pests in agriculture. Similarly, essential oilloaded solid lipid nanoparticles were also useful for the formulations of Nano-pesticides (Liu et al. 2006).

Nano-silica, a type of unique nanomaterial, is prepared from silica. It has many applications in medicine and drug development as catalyst and most importantly, it can be used as nano-pesticide Barik et al. (2008). The mechanism of pest control using Nanosilica is based on the fact that pests used a variety of cuticular lipids for protecting their water barrier and thereby prevent death from desiccation. But Nanosilica gets absorbed into the cuticular lipids by physiosorpation and thereby causes death of pests purely by physical means when applied on leaves and stem surface.

In Fayoum University nematology lab we use new technology based on extracting natural Nematicides from Certain medicinal plant ( as green chemistry) to be used against nematode.

In 1993, 2005 Haroon, S.A , M. Maged, S.M Abdeleahab found out that Eight medicinal plants were chosen to find out their effects on Meloidogyne incognita ( kofid \& white) under green house, laboratory and tissue culture conditions. These plants are ambrosia maritime, alocasia macrorrhizos, peppermint mwntha piparita, Tagetes, calendula officinalis, hyoscyamus muticus, sweet majorana, linum usitatissimum, trigonella foenum-graecum. Ambrosia proved to be the most effective plant for causing very high mortality likewise, origanum, calendula, hyoscyamus but of second stage larva linseed caused considerable percentages of the nematode mortality. The least values of mortality obtained with /menthe, Alocosia and Faenugreek. Ambrosia, Hyoscyamus and Origanum reduced remarkably the nematode population in both soil and root, the nematode failed to reproduce in such plants, where the nematode build up were $0.05,0.07$ and 0.12 , respectively. No galls or egg masses were obtained on their roots. Calendula reduced population to a very low extent and nematode failed to multiply as the value of buildup was 0.9 , little numbers of galls and egg masses were counted on its roots. On the other hand, the nematode population in linseed increased to a little extent. The estimated nematode build-up was 1.05 and the root gall index was 2 .

Development and reproduction of root knot nematode in the tested medicinal plants were studied under tissue culture conditions. Root explants of such plats as well as tomato were cultured in Gambrg;s B5 medium. In Ambrosia and Hyosyamus no development stages were detected without evidence of the nematode maturation or gall formation.

But during our work we found out that some problems with the new developed bio nano nematicide are existing such as photolysis, hydrolysis or deviation away from the infected land by wind or rain. So we will promote us to use Nano capsulated packaging as bio-Nano nematocides of high capacity that melting and decomposition within the plant, stability and consistency within the space application that reduces the amount of chemical materials used and reduce the application time operations again as they provide the best and easiest way to penetrate the plants of several ways as a result of their small size and speed of deployment.

As a conclusion Bio-nanotechnology has the potential to revolutionize the different sectors of the agricultural and food industry with modern tools for 
the treatment of diseases, rapid disease detection, enhancing the ability of plants to absorb fertilizers, also smart sensors and smart delivery systems will help the agricultural industry combat viruses and other crop pathogens (Rickman et al. 1999), Tiny sensors and monitoring systems enabled by nanotechnology will have a large impact on future precision farming methodologies. Ultimately, precision farming, with the help of smart sensors, will allow enhanced productivity in agriculture by providing accurate information, thus helping farmers to make better decisions (Cioffi et al. 2004).

In the near future, Nano-based catalysts will be available which will increase the efficiency of all different kind pesticides, allowing lower doses to be used, Nanotechnology will also protect the environment indirectly through the use of alternative (renewable) energy supplies, and filters or catalysts to reduce pollution and clean up existing pollutants (Tungittiplakorn et al. 2005).

Recently, Bhattacharyya et al. (2011) reviewed applications of nanotechnology in different fields like Nano-food, Nano food packaging and Nano-farming and also emphasized on nanoparticles and their effects on ecological balance.

Despite these great advantages, nanotechnology applications in the agricultural sector are still marginal and have not yet made it to the market or other industrial sector. Most of research mainly claimed by the academic sector or small enterprises, and not reaching large industries. The trends of patent applications (from agro-chemical companies) are continuously growing, but no new Bio Nano-based products for the agricultural sector have reached the market yet.

But the bright side that Several scientific publications in agricultural nanotechnology, was published especially for disease management, crop protection minimize nutrient losses in fertilization and increase yields through optimized water and nutrient and in the field of plant breeding and genetic transformation.

So hopefully that bio Nano technology applications in agricultural production are entering the market phase, soonest it is important to look at it with ensoziasm for better agriculture production that can compete in the technological revolution that developing fast all over the world.

\section{References}

Barik TK, sahu B, swain V (2008) nano-srlica-from medicine to pest control. Parasitol Res 103:253-258

Bhattacharyya A, Datta ps, chaudhuri p, Barik Bp (2011) nanotechnology: a new frontier for food security in socio economic devel-opment. In: Proceeding of disaster, risk and vulnerability conference 2011 held at school of environmental sciences, Mahatma Gandhi university, India in association with the applied Geoinformatics for society and Environment, Germany, 12-14 march 2011 .

Cioffi N, Torsi L, Ditaranto N, sabbatini L, Zambonin PG, Tantillo G, Ghibelli L, D'Alessio M, BleveZacheo T, Traversa E (2004) Antifungal activity of polymer-based copper nano-composite coatings. Appl Phys Lett 85:2417-2419.

Dhawan AK, Peshin $R$ (2009) Integrated pest management: concept, opportunities and challenges. In: Peshin P, Dhawan AK (eds) Integrated Pest management: innovationdevelopment process. Springer, Dordrecht, Netherlands, PP 51-81 .

Haroon S.A. and Ekram F. Hashem (1993). Naturally occurring insecticides. Part 1: Insecticidal activity of five plant's extracts on the fourth and fifth instar larvae of Spodoptera littorals (Boisd) and root-knot nematode (Meloidogyne incognita, Kof oid et White). 5th Nat. Conf. of Pests \& Dis. of Veg. \& Fruits in Egypt, Ismailia, pp. 109-132.

Haroon, S. A., M.S. M. S. Magd, S.M. Abdel. Wahab and E.F.M.M. Hashim (1993) "Biocontrol of root knot nematode Meloidogyne incognita using certain medicinal plants under field, lab and tissue culture conditions" 5th Nat. Conf. of pests \& Dis of Veg. \& Fruits in Egypt, Ismailia P. 539-558

Haroon, S.A., E. F. Hashem , M.A.. Sayed and H. Metwally , (2005). Biodegradation of Pirimiphos-Methyl Using two types of Microorganisms Isolated from Fayoum Governorate Soil. Fayoum Journal of Agricultural Research and Development.19(2):112

Khan, A., Mohd, A.,Moh, T., Bushra, R., Kavita, P., \& Mansour, A. S.(2017). Phytochemical investigation, nematostatic and nematicidal potential of weeds extract afainst the root knot nematode. Melodogyne incognita in vitro. Asian journal of biological sciences, 10, 38-46

Liu F, Wen LX, Li ZZ, Yu W sun HY, Chen JF (2006) Porous hollow Silica nanoparticles as controlled delivery system for water soluble pesticide. Mat Res Bull 41:2268-2275.

Luc, M. , Sikora, R.A., \& Bridge, J. (2005). Plant parasitic nematodes in subtropical and tropical agriculture $(\mathrm{P}$ 871).CAB international, Wallingford, UK. Https://doi.org/10.1079/9780851997278.0000

Rickman D, Luvall JC, shaw J, mask P, Kissel D, Sullivan D (1999) Precision agriculture: changing the face of farming. Geotimes festura article. www.ghcc.msfc.nasa.gove/precisionag/. Accessed 19 november, 2011.

Tungittiplakorn W, cohen C, lion LW (2005) Engineered polymeric nanoparticles for bioremediation of hydrophobic contaminants. Environ sci Technol 39(5): 1354-1358. 